\title{
The Effects of Gender and Obesity on Myocardial Tolerance to Ischemia
}

\author{
C. CLARK ${ }^{1}$, W. SMITH ${ }^{1}$, A. LOCHNER ${ }^{1}$, E. F. DU TOIT ${ }^{2}$ \\ ${ }^{1}$ Division of Medical Physiology, Department of Biomedical Sciences, Faculty of Health Sciences, \\ University of Stellenbosch, Tygerberg, Cape Town, South Africa, ${ }^{2}$ School of Medical Science, \\ Griffith University, Gold Coast Campus, QLD, Australia
}

Received March 30, 2010

Accepted August 5, 2010

On-line November 29, 2010

\section{Summary}

Obesity is increasing at an alarming rate globally. Several studies have shown that premenopausal women have a reduced risk of CV disease and a reduced myocardial susceptibility to ischemia/reperfusion injury. The effect of obesity on myocardial tolerance to ischemia in women has not been established. To determine how obesity affects myocardial susceptibility to ischemia/reperfusion injury in both males and females, we fed male and female Wistar rats a high caloric diet (HCD) or a control rat chow diet (CD) for 18 weeks. Rats were subsequently fasted overnight, anesthetized and blood was collected. In separate experiments, 18-week-fed (HCD and CD) rats underwent $45 \mathrm{~min}$ in vivo coronary artery ligation (CAL) followed by 2 hours reperfusion. Hearts were stained with TTC and infarct size determined. Both male and female HCD fed rats had increased body and visceral fat weights. Homeostasis model assessment (HOMA) index values were $13.95 \pm 3.04$ for $C D$ and $33.58 \pm 9.39$ for $\mathrm{HCD}$ male rats $(p<0.01$ ) and 2.98 \pm 0.64 for $C D$ and $2.99 \pm 0.72$ for HCD fed female rats. Male $\mathrm{HCD}$ fed rats had larger infarct sizes than $\mathrm{CD}$ fed littermates $(43.2 \pm 9.3 \%$ vs. $24.4 \pm 7.6 \%, p<0.05)$. Female HCD and $\mathrm{CD}$ diet fed rats had comparable infarct sizes ( $31.8 \pm 4.3 \%$ vs. $23.9 \pm 3.3 \%$ ). We conclude that male rats on the HCD became viscerally obese, dyslipidemic and insulin-resistant, while female HCD fed rats became viscerally obese without developing dyslipidemia or insulin resistance. Obesity increased myocardial infarct size in males but not the females.
\end{abstract}

\section{Key words}

Obesity $\bullet$ Gender $\bullet$ Myocardial infarction

\section{Corresponding author}

E. F. du Toit, School of Medical Science, Griffith University Gold Coast, Parklands Drive, Southport, QLD, 4217, Australia. Fax: 07555 28908. E-mail: j.dutoit@griffith.edu.au

\section{Introduction}

The incidence of obesity is increasing at an alarming rate globally. According to a 2005 World Health Organization (WHO) survey 1.6 billion of the world's adults were overweight and another 400 million obese. It is predicted that by $2015,2.3$ billion adults will be overweight and more than 700 million will be obese. Obesity has increased exponentially in women and has lead to the publication of guidelines for the prevention of cardiovascular disease in women (Mosca et al. 2007). Obesity predisposes individuals to cardiovascular disease and more specifically myocardial infarction and heart failure (Kenchaiah et al. 2002, Sowers et al. 2003, Yusuf et al. 2005).

Several studies have shown that premenopausal women have a reduced risk of cardiovascular disease when compared with men (Barrett-Connor et al. 1997, Crabbe et al. 2003) but that cardiovascular disease increases after menopause (Hayward et al. 2000). A phenomenon thought to be due to the presence of female sex hormones before menopause. The relevance of these observations were however questioned when it became evident that hormone replacement therapy was unable to protect postmenopausal women against cardiovascular disease (Rossouw et al. 2002). Although some studies suggest that the female myocardium is more resistant to ischemia/reperfusion injury than the male myocardium (Mehelli et al. 2002, Bae and Zhang 2005, Gabel et al. 2005, Wang et al. 2006), the effect of obesity on myocardial tolerance to ischemia in both males and females remains unresolved. 
Data from recent studies suggest that obesity may alter myocardial metabolism leading to compromised cardiac function and tolerance to ischemia (Poirier et al. 2006, Lopaschuk et al. 2007). Elevated circulating lipids may promote increased myocardial fatty acid uptake and utilization which could decrease both myocardial 1) efficiency under normoxic conditions, (Tuunanen et al. 2006, Lopaschuk et al. 2007) and, 2) tolerance to ischemia (Opie 1998). Obesity may also promote cardiac lipid accumulation which has been implicated in the etiology of insulin resistance (Lopaschuk et al. 2007). Excessive myocardial free fatty acid utilization during ischemia is also potentially detrimental as it not only inhibits glucose oxidation (Tuunanen et al. 2006), but fatty acids also require more oxygen for ATP production when compared with glucose (Wallhaus et al. 2001).

Obesity is also a risk factor for insulin resistance (Bjorntrop 1993). Several mechanisms have been proposed to explain how increased adiposity interferes with insulin signalling and glucose uptake and utilization. Increased fat accumulation in insulin sensitive tissues causes dysfunction of the insulin signalling cascade by activating PKCO which inhibits IRS-1 (insulin receptor substrate 1) and PI3-K (phosphoinositide 3-kinase) activity and causes decreased GLUT-4 translocation and glucose uptake (Boden and Schulman 2002). Ischemic hearts rely on glucose as the primary fuel to produce ATP through glycolysis with insulin resistance compromising the heart's ability to tolerate an ischemic event (Lopaschuk et al. 2002). The effect of gender on obesity induced insulin resistance is controversial. Although observations from several laboratory (Horton et al. 1997, Gomez-Perez et al. 2008) and clinical studies (Ferrara et al. 2008, Vistisen et al. 2008) have suggested that obesity does not affect insulin sensitivity in females, others have shown that both genders are prone to obesity induced insulin resistance and subsequent diabetes (CoatmellecTaglioni et al. 2003, Cordero et al. 2009).

Adiponectin is an adipocytokine that is elevated in the serum of women when compared with men (Ryo et al. 2004, Costacou et al. 2005). It improves insulin sensitivity of insulin sensitive organs (Yamauchi et al. 2001, Kubota et al. 2002, Stefan et al. 2002), decreases hepatic glucose production (Batterham et al. 2002) and may consequently protect the heart against ischemic/reperfusion injury. Similarly, estrogen is purported to improve lipid profiles (Pedersen et al. 2004), protect against hyperglycemia (Rincon et al. 1996, Louet et al. 2004) and be cardioprotective during ischemia (Wang et al. 2006). The latter effects of estrogen may be by: 1) inducing nitric oxide synthase (NOS) production which in turn inhibits the L-type $\mathrm{Ca}^{2+}$ channels (Groné et al. 1998) or, 2) by differentially activating MAPK to mediate this protection (Wang et al. 2006).

Effects of obesity on this apparent increased tolerance to ischemia in women is however unknown. Previous studies in our laboratory have shown that diet induced obesity in male rats increased heart susceptibility to ischemia/reperfusion injury ( $\mathrm{Du}$ Toit et al. 2005, 2008). We had however not tested the effects of this high caloric diet (HCD) in female rats. Preliminary observations by our group had suggested that body weight gain in female rats on this diet was lower than in their male littermates. In addition, no other studies had carefully documented body weight gain and visceral fat accumulation in female rats on this HCD. We therefore wished to determine whether: 1) the female rats would become obese when subjected to a high caloric diet (HCD), 2) the obesity induced systemic insulin resistance in the female rats and, 3) obesity impacts on myocardial tolerance to ischemia in the female rats. Finally, we wished to determine how obesity influenced circulating adiponectin and estrogen levels in these animals and whether there was an association between the levels of these peptides and insulin sensitivity and myocardial tolerance to ischemia.

\section{Methods}

\section{Feeding program}

Age matched ( 8 week old) male and female Wistar rats were put on a high caloric diet (HCD) or a control diet (CD) for 18 weeks (Pickavance et al. 1999, Du Toit et al. 2008). The CD fed rats had a total energy intake of $371 \pm 18 \mathrm{~kJ} /$ day (60 \% carbohydrates, $30 \%$ protein, and $10 \%$ fat) and the HCD fed rats had a total energy intake of $570 \pm 23 \mathrm{~kJ} /$ day (65\% carbohydrates, $19 \%$ protein and $16 \%$ fat). The increased caloric intakes in the HCD fed rats were achieved due to voluntary hyperphagia. The choice of the dietary composition for our study was motivated by the fact that global and particularly African urbanisation is associated with an increase in the incidence of obesity. The increase in the incidence of obesity in Africa has been attributed to an increase in the dietary fat (Khan and Bowman 1999, MacIntyre et al. 2002) and refined sugar (Khan and Bowman 1999) content in the diet. The typical diet of 
urban Africans now more closely resembles the Western diet with a high fat and carbohydrate content (Kruger et al. 2002, Bourne et al. 2002). This change in the rat diet would therefore mimic the change in diet often experienced with urbanisation where both carbohydrate and fat content of the diet may increase (Khan and Bowman 1999).

The rats were supplied by, and housed in the Central Research Facility of the Faculty of Health Sciences at the University of Stellenbosch (AAALAC accredited). Animals were provided with fresh food daily and had ad libitum access to food and water and were housed in facilities with a 12-hour day-night cycle at $23{ }^{\circ} \mathrm{C}$.

The study was approved by the Committee for Experimental Animal Research of the Faculty of Health Sciences, University of Stellenbosch. All animals received humane care in accordance with the Principles of Laboratory Animal Care of the National Society for Medical Research and the Guide for the Care and use of Laboratory Animals of the National Academy of Sciences (NIH publication no 80-23, revised 1985).

\section{Experimental design}

Sixty four Wistar rats (32 male and 32 female) were randomly divided in two groups that were placed on either the $\mathrm{CD}$ or the HCD for 18 weeks. Within each group, 10 rats were randomly selected for in vivo infarct size quantification and the remaining 6 were used for biochemical analysis.

\section{In vivo infarct induction and infarct size quantification}

Rats were anesthetized with an intraperitoneal injection of ketamine $(7.5 \mathrm{mg} / \mathrm{kg})$ and medetomidine $(0.5 \mathrm{mg} / \mathrm{kg})$, intubated, and placed on a rodent ventilator (Harvard Instruments, Model 683) before being placed in a pediatric incubator maintained at a temperature of $34.5^{\circ} \mathrm{C}$. Rat core temperature was monitored using a rectal temperature probe and was maintained at $36-37{ }^{\circ} \mathrm{C}$ throughout the experiment.

Rats were placed on their right side, the thorax shaved and a left thoracotomy performed. The ribs were separated using a rodent retractor (Aesculap, Melsungen, Germany) and the pericardium removed. The left anterior descending (LAD) coronary artery was ligated using an Ethicon silk suture. Hearts were subjected to $45 \mathrm{~min}$ regional ischemia before hearts were reperfused for $120 \mathrm{~min}$ (Thim et al. 2006). Myocardial reperfusion was initiated by release of the silk suture. During CAL and reperfusion the thoracic cavity was covered with a sterile saline solution saturated swab to prevent excess fluid loss and dehydration. Rats were also injected with $2 \mathrm{ml}$ of sterile saline intraperitonealy every 30 minutes to compensate for any fluid loss which may have occurred due to the ventilation.

After 120 min reperfusion, hearts were excised, mounted on an isolated Langendorff perfusion system and perfused with a Krebs-Henseleit bicarbonate buffer within $30 \mathrm{sec}$ of excision from the rat. This isolated heart perfusion lasted $60 \mathrm{sec}$ to allow for staining with Evans blue dye. The coronary artery was reoccluded and the heart was stained with $600 \mu$ of Evan's Blue Dye (Sigma, Saint Louis, Missouri, USA) administered through the aortic cannula. Hearts were frozen at $-20{ }^{\circ} \mathrm{C}$ overnight after which triphenyl tetrazolium chloride (TTC) was used to delineate the viable and necrotic myocardium. Infarct size was expressed as a percentage of the area at risk.

The sham-operated animals underwent the same surgical procedure described above except that the suture that was passed under the LAD coronary artery was not fastened. The same TTC staining procedure was followed. Necrotic tissue was present where the suture passed through the myocardium under the LAD coronary artery but this necrotic tissue represented less than $2 \%$ of the left ventricular area at risk. One animal was lost during the initial surgical procedure during induction of coronary artery ligation due to excessive bleeding.

\section{TTC staining}

After freezing, hearts were cut into 5-7 transverse slices, each approximately $2 \mathrm{~mm}$ in size. Heart slices were immersed in a buffered triphenyltetrazolium chloride (TTC) solution at room temperature (protected from light) for 15-20 minutes. They were subsequently immersed in $5 \mathrm{ml}$ of formaldehyde for 3 hours to enhance any color differences.

\section{Biochemical analysis}

The animals which were set aside for biochemical analysis were fasted for 10 hours, anesthetized and blood was collected for biochemical analysis. Blood was collected by cardio-puncture after performing a thoracotomy to access the heart. The hearts from these animals were not used for the infarct size determinations as fasting and consequent glycogen depletion of the heart compromises myocardial tolerance to ischemia/reperfusion. The peritoneal and retroperitoneal fat was removed and weighed (Sartorius 
Pty. Ltd, Johannesburg, South Africa).

For serum collection, blood samples were placed in serum separation tubes (BD Vacutainer tubes) and stored on ice for 20 minutes before centrifugation (Eppendorf Centrifuge 5403, Hamburg, Germany) at $2000 \mathrm{~g}$ at $4{ }^{\circ} \mathrm{C}$ for 10 minutes. Serum was stored at $-80{ }^{\circ} \mathrm{C}$ until assays could be performed. The assays were all done within 1-2 weeks of collection of the serum samples. Insulin (Coat-A-Count ${ }^{\circledR}$ Insulin, Siemens Medical Solutions Diagnostics, California, USA), estrogen (Assay Designs' Correlate-EIA ${ }^{\mathrm{TM}}$, Michigan, USA) and adiponectin (AdipoGen, Seoul, Korea) were determined according to the manufacturers' instructions. The respective serum concentrations were analyzed using a radioimmunoassay (RIA), an immunoassay and two enzyme-linked immunosorbant assay's (ELISA).

Serum triglycerides, high density lipoproteins (HDL) cholesterol, low density lipoproteins (LDL) and cholesterol levels and glucose levels were determined in fresh blood using a Cardiochek ${ }^{\circledR}$ lipid analyzer (Cardiocheck, Indianapolis, USA) and a glucometer (GlucoPlus ${ }^{\mathrm{TM}}$ Inc, Québec, Canada) respectively.

In order to assess insulin resistance in these animals the homeostasis model assessment (HOMA) index was determined. Fasting blood glucose and insulin levels were used to determine the HOMA index using the standard formula: [fasting insulin $(\mu \mathrm{IU} / \mathrm{ml}) \mathrm{x}$ fasting glucose $(\mathrm{mmol} / \mathrm{l})] / 22.5$.

\section{Statistical analysis}

All results were expressed as the mean \pm standard error of the mean (S.E.M.). For multiple comparisons, a Two-way ANOVAs was used followed by a Bonferroni post hoc test. A p-value of less than 0.05 was considered to be significantly different.

\section{Results}

\section{Body weights}

Rats were age matched and male and female rats therefore had different body weights at the start of the study. Female Wistar rats are known to be 100-110 grams lighter than their male littermates at 8 weeks (Table 1). Male and female rats on the HCD had increased body weights compared with their $\mathrm{CD}$ fed littermates (Fig. 1A). The percentage weight gain was higher in both male and female rats on the HCD (Table 1). Visceral fat content was also higher in HCD fed male and female rats compared with CD fed rats (Fig. 1B).
Table 1. Initial body weights and percentage body weight gain for male and female rats after 18 weeks on the respective diets.

\begin{tabular}{lcc}
\hline & Male & Female \\
\hline Control Diet (CD) & $303.6 \pm 4.9 \mathrm{~g}$ & $198.4 \pm 4.6 \mathrm{~g}$ \\
High Caloric Diet (HCD) & $308.2 \pm 5.4 \mathrm{~g}$ & $206.5 \pm 4.8 \mathrm{~g}$ \\
Control Diet (CD) & $45 \pm 4 \%$ & $23 \pm 3 \%$ \\
High Caloric Diet (HCD) & $58 \pm 5 \%{ }^{\#}$ & $36 \pm 6 \%{ }^{\#}$ \\
\hline
\end{tabular}

\# $\mathrm{p}<0.05$ vs. control diet, $\mathrm{n}=16$ for each experimental group.

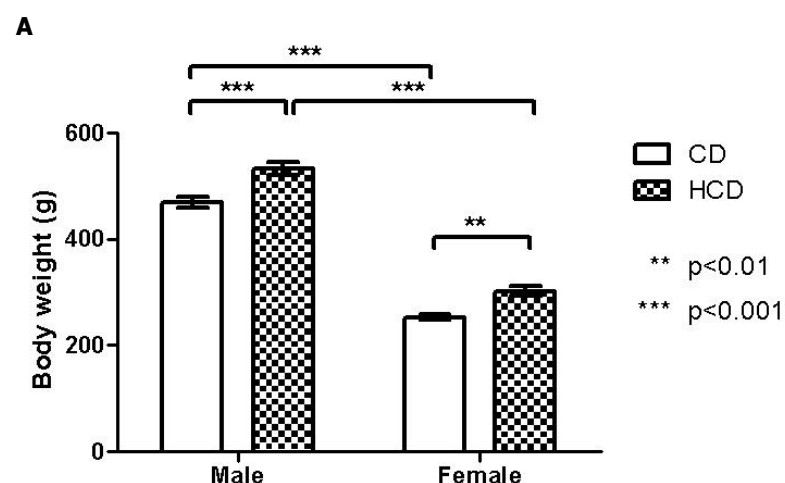

B

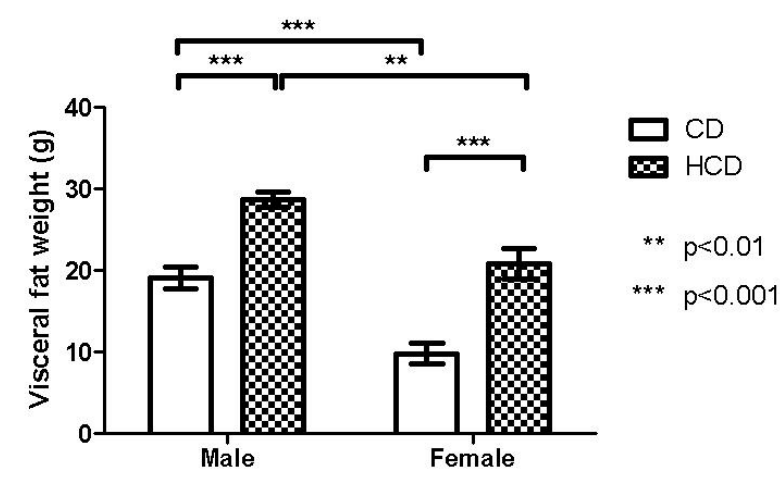

Fig. 1. (A) Final body weight of male and female, $C D$ and $H C D$ fed rats. (B) Visceral fat weight of male and female, $C D$ and $H C D$ fed rats. All values are expressed as mean \pm S.E.M. $n=16$ for each experimental group.

Blood and serum lipid, glucose and insulin levels

Serum triglyceride levels were elevated in the male HCD fed rats but not in the HCD fed female rats (Fig. 2A). Triglyceride levels were however significantly lower in HCD fed females than HCD fed males $(0.78 \pm 0.11 \mathrm{mmol} / \mathrm{l}$ for females vs. $1.31 \pm 0.08 \mathrm{mmol} / 1$ for males, $\mathrm{p}<0.001)$. Serum total cholesterol levels were below the assay detection limit $(2.5 \mathrm{mmol} / \mathrm{l})$ for the females (Fig. 2B) and similar between male CD and HCD fed groups (Fig. 2B). Serum HDL cholesterol levels were similar in all four groups (Fig. 2C). 
A

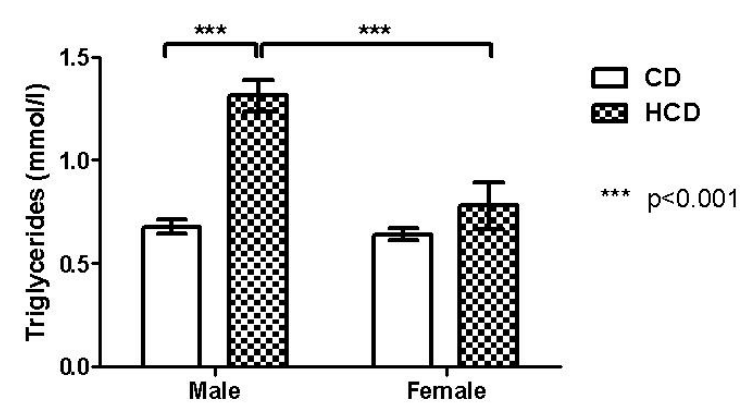

B

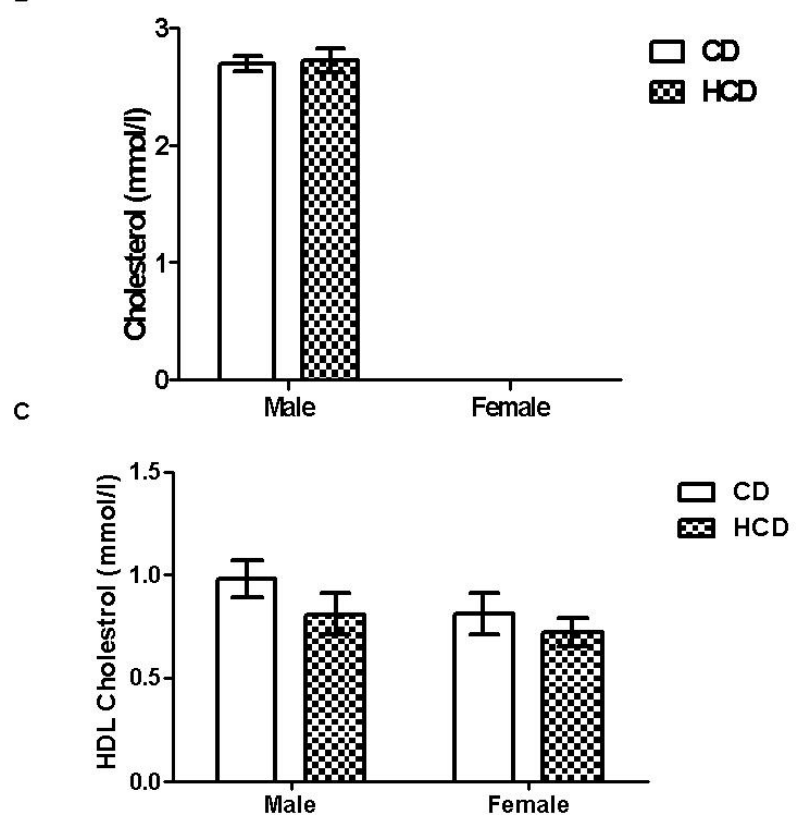

Fig. 2. (A) Fasting serum triglyceride levels of male and female, $\mathrm{CD}$ and $\mathrm{HCD}$ fed rats. (B) Fasting serum total cholesterol levels of male and female, $C D$ and HCD fed rats. (C) Fasting serum HDL cholesterol levels of male and female, CD and HCD fed rats. All values are expressed as mean \pm S.E.M. $n=6$ for each experimental group.

Fasting blood glucose levels were elevated in HCD fed compared with CD fed male rats (Fig. 3A). There were no differences in fasting blood glucose levels in the female rats. Male obese rats also had higher fasting blood glucose levels than their female obese littermates (Fig. 3A).

Male HCD fed rats had elevated insulin levels compared with $\mathrm{CD}$ fed rats (Fig. 3B). No differences were observed between the two female groups. Male CD fed rats however also had higher insulin levels than $C D$ fed females and HCD fed male rats had higher insulin levels than HCD fed female rats (Fig. 3B).

HOMA values were increased in HCD fed males compared with the $\mathrm{CD}$ fed males (Fig. 3C). HOMA values were also increased in the $\mathrm{HCD}$ fed male rats compared with the HCD fed females (Fig. 3C).
A

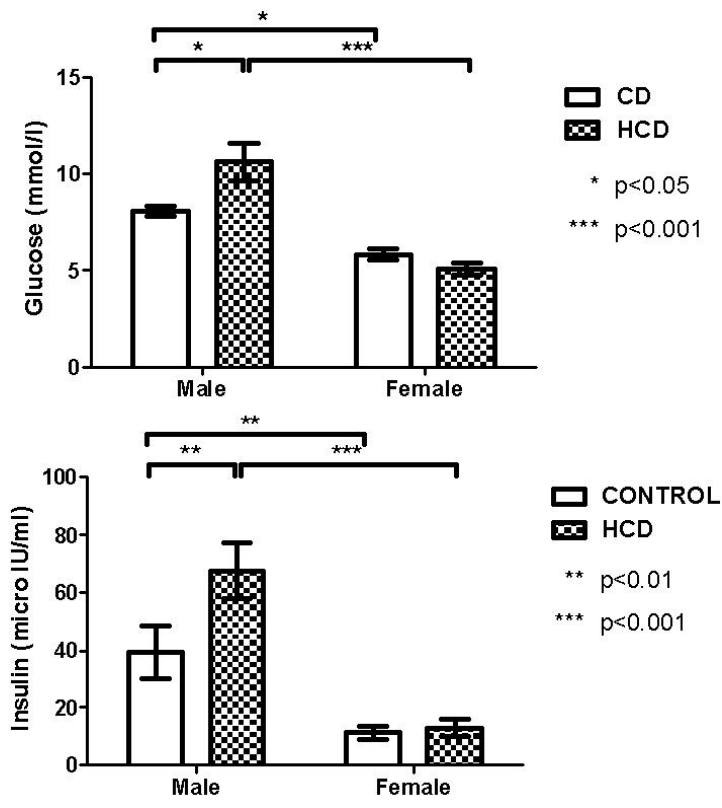

C

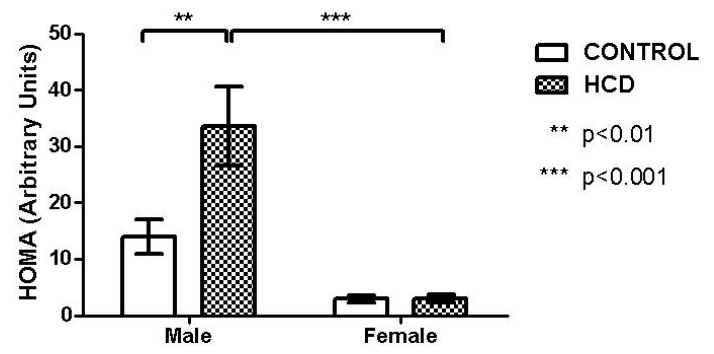

Fig. 3. (A) Fasting blood glucose levels of male and female, $C D$ and HCD fed rats. (B) Fasting serum insulin levels of male and female, CD and HCD fed rats. (C) HOMA values for male and female, $C D$ and $H C D$ fed rats. All values are expressed as mean \pm S.E.M. $n=6$ for each experimental group.

\section{Effect of obesity on myocardial infarct size}

Infarct was expressed as a \% of the area at risk. The area of the left ventricle at risk was similar for all four experimental groups (male CD - 45.2 $\pm 8.2 \%$, male HCD $43.6 \pm 10.4 \%$, female CD - 46.8 $\pm 10.5 \%$ and female HCD - 40.7 $\pm 7.0 \%$ ). Infarct size was increased in HCD fed compared with $\mathrm{CD}$ fed male rats (Fig. 4). There were no differences in infarct size between the female groups but myocardial infarct size was reduced in female rats fed HCD compared with males on the same diet. Infarct size was similar for male and female rats on the CD (Fig. 4).

\section{Circulating adiponectin and estrogen levels}

The HCD had no effect on serum adiponectin levels in either the male or the female rats. Female obese (on HCD) rats however had elevated adiponectin levels compared to the obese male littermates (23.48土 $0.94 \mu \mathrm{g} / \mathrm{ml}$ vs. $19.92 \pm 0.74 \mu \mathrm{g} / \mathrm{ml}, \mathrm{p}<0.001)$. Male and 


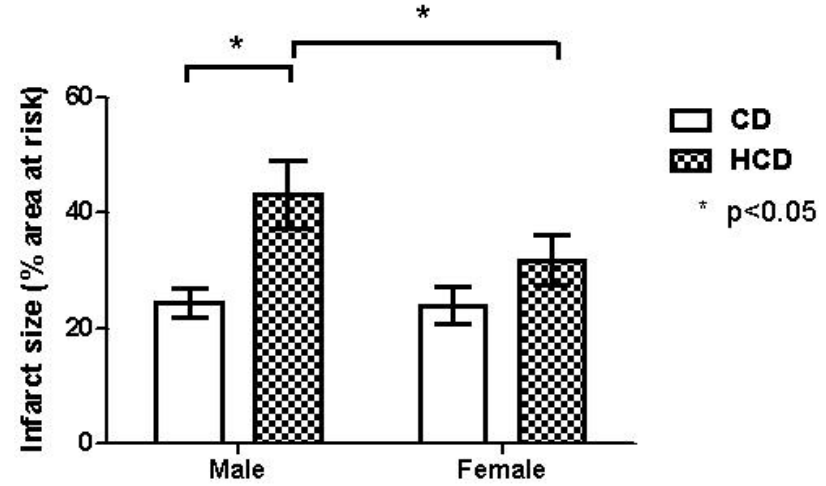

Fig. 4. Infarct size (as a percentage of the area at risk) of male and female, $C D$ and $\mathrm{HCD}$ fed rats. All values are expressed as mean \pm S.E.M. $n=9-10$ for each experimental group.

female $\mathrm{CD}$ fed rats had similar adiponectin levels (male $\mathrm{CD}-19.00 \pm 0.73 \mu \mathrm{g} / \mathrm{ml}$ and female $\mathrm{CD}-21.46 \pm$ $0.74 \mu \mathrm{g} / \mathrm{ml})$

The fasting serum estrogen levels were similar for all groups at the time of blood collection and experimentation (male CD - 971.3 $\pm 22.4 \mathrm{pg} / \mathrm{ml}$, male

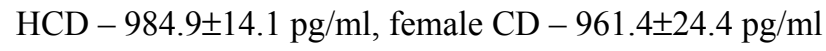
and female $\mathrm{HCD}-981.0 \pm 3.9 \mathrm{pg} / \mathrm{ml}$ ).

\section{Discussion}

We found that both male and female rats were prone to visceral obesity when subjected to a HCD. This visceral obesity was associated with dyslipidemia, elevated insulin and glucose levels and insulin resistance (as assessed using the HOMA) in the male but not in the female rats. This obesity and decreased insulin sensitivity was also associated with increased myocardial infarct sizes in male but not female rats. The maintained insulin sensitivity in viscerally obese female rats may be due to the normal circulating lipids and increased circulating adiponectin levels in females when compared with their obese male littermates. The normal tolerance to ischemia observed in the female rats may be due to their normal insulin sensitivity but cannot be attributed to elevated circulating estrogen levels in these animals at the time of experimentation.

Effect of obesity on serum lipids and insulin resistance in male and female rats

The effects of obesity and the metabolic syndrome on cardiovascular risk factors in women are controversial (Coatmellec-Taglioni et al. 2003, RegitzZagrosek et al. 2007, Cordero et al. 2009). Cordero et al. (2009), and others (Coatmellec-Taglioni et al. 2003) have proposed that women may be as prone, if not more prone to obesity induced insulin resistance than men. Conversely, data from animal studies suggest that females may be protected against obesity (Gomez-Perez et al. 2008, Ferrara et al. 2008, Vistisen et al. 2008) or high sucrose diet (Horton et al. 1997) induced insulin resistance.

We found that basal insulin levels were lower in female lean rats than in their lean male littermates (Fig. 3). This is in agreement with the findings of another study comparing the effects of a high fat diet on fasting insulin levels in lean rats (Gomez-Perez et al. 2008). This group found that fasting serum insulin levels were lower in female than male rats and that the high fat diet exacerbated insulin resistance in male rats.

We found that both male and female rats put on a high caloric diet (containing increased carbohydrates and fats) had significantly elevated body and visceral fat weights. The increased body weight was associated with elevated serum triglyceride levels and insulin resistance in the male rats while there was no change in lipid levels or insulin sensitivity in the female rats. These observations are in agreement with the data showing that high fat diet induces obesity, dyslipidemia and insulin resistance in male rats (Gomez-Perez et al. 2008), but not in females (Gomez-Perez et al. 2008, Aubin et al. 2008). A similar study by Thakker and co-workers (2006) found that a high fat diet induced obesity and dyslipidemia in both male and female mice without causing insulin resistance in the female animals. Male mouse fasting insulin levels were four-fold higher in obese male than obese female mice and the male mice were insulin resistant as determined using the HOMA-IR (insulin resistance) index. Similarly, in another study high sucrose diets increased body weight in female rats without causing insulin resistance (Horton et al. 1997). There is also strong evidence to suggest that estrogens decrease noradrenalin induced lipolysis in women by up-regulating the $\alpha-2$ adrenergic anti-lypolytic receptors in adipose tissue (Pedersen et al. 2004). The absence of an effect of the HCD on total cholesterol levels in the rats in this study is consistent with our observations (Du Toit et al. 2008) and those of others (Roach et al. 1993, Ferdinandy et al. 1997) and is believed to be due to down-regulation of hepatic cholesterol synthesis in response to increased dietary cholesterol consumption in the rat (Roach et al. 1993).

Potential mechanisms for obesity induced insulin resistance

A role for elevated serum lipids in the genesis of 
peripheral insulin resistance was proposed several years ago (Kraegen et al. 1991). We now believe that elevated plasma triglycerides associated with obesity cause intramuscular triglyceride accumulation despite the concomitant increased fatty acid oxidation rates in the muscle (Kraegen et al. 1991, Turner et al. 2007). This may explain the increased insulin sensitivity observed in female rats in our study where lipid profiles remained normal despite the increased body and visceral fat weights of the HCD fed female rats. Our findings are consistent with those of Gomez-Perez and co-workers (2008) who found that a high fat diet induced more severe insulin resistance (as assessed using HOMA) in the male than the female rats. This was despite the fact that the body weight gain in the female rats was $38 \%$ compared with the moderate weight gain of $16 \%$ observed in the male rats in that study.

The proposed insulin sensitizing effects of adiponectin are well documented (Berg et al. 2001, Combs et al. 2001, Fruebis et al. 2001, Ryo et al. 2004). Yamauchi and co-workers (2001) demonstrated a very strong correlation between elevated adiponectin levels and improved insulin sensitivity. They also demonstrated how chronic exogenous adiponectin administration improved insulin sensitivity in mice. We could not demonstrate differences in the levels of circulating adiponectin between $\mathrm{CD}$ fed and HCD fed male rats or between lean and obese female rats but found that circulating adiponectin levels were higher in female obese than in male obese rats. The elevated adiponectin levels in female obese rats may improve insulin sensitivity in these animals and therefore protect them against obesity induced insulin resistance.

Estrogen also plays a role in glucose homeostasis and metabolism. Estrogen protects animal models of diabetes against hyperglycemia by increasing glucose uptake into muscle and decreasing hepatic glucose synthesis (Rincon et al. 1996, Louet et al. 2004). Although we did not see any differences in estrogen levels in the serum of our rats at the time of blood collection and experimentation, we believe that these rats were pre-menopausal and would have been affected by the additional estrogen present in females at certain stages of the estrus-cycle.

The effects of obesity and consequent insulin resistance on myocardial susceptibility to ischemia/reperfusion injury in male and female rats

Our group has previously shown that male rats on the high caloric diet became obese, dyslipidemic and insulin resistant and were more prone to ischemic/reperfusion injury (Du Toit et al. 2005, 2008). The effects of gender on myocardial susceptibility to ischemia is however controversial. Studies using isolated perfused hearts (Wang et al. 2006) or isolated cardiomyocytes (Ranki et al. 2001) have demonstrated that the hearts of female rats are more resistant to ischemia/reperfusion damage than their male counterpart. Similarly Cross and co-workers (1998, 2002, 2003) have demonstrated increased resistance to ischemia/reperfusion injury in conditions where intracellular calcium was elevated prior to ischemia. They also demonstrated that estrogen may play a cardioprotective role in females as ovarectomised rats had levels of ischemic injury that resembled those of males (Cross et al. 2002). Despite these positive findings, a large scale clinical trial has failed to show any cardioprotective benefits from hormone replacement therapy in postmenopausal women (Rossouw et al. 2002). It was proposed that the adverse effects observed in the latter study may be related to prothrombotic effects of progestins (Rossouw et al. 2002). We were unable to demonstrate an increased tolerance to ischemia in $\mathrm{CD}$ fed female rats when compared with males when using this in vivo model of ischemia/reperfusion. This may be due to the fact that we performed all the experiments at a stage in the estrus cycle when estrogen levels were low and comparable with males. This was achieved by performing all experiments on the same day of the estrus cycle of the rat. The absence of differences in estrogen levels in the male and female rats during the time of experimentation in this in vivo model would eliminate the possible receptor mediated protective effects of estrogen. The long term beneficial effects of estrogen that include its lipid (Pedersen et al. 2004) and glucose (Rincon et al. 1996, Louet et al. 2004) modulating effects cannot however be discounted.

\section{Conclusions}

We conclude that visceral obesity causes dyslipidemia and insulin resistance in male but not female rats. The obese insulin resistant male rats were more prone to ischemic/reperfusion injury than their lean littermates. Obese female rats on the HCD were not dyslipidemic or insulin resistant and were more resistant to ischemic/reperfusion injury than their male obese littermates. 


\section{Conflict of Interest}

There is no conflict of interest.

\section{Acknowledgements}

This study was supported by funding from the South African National Research Foundation and the Harry and Doris Crossley Foundation.

\section{References}

AUBIN MC, LAJOIE C, CLEMENT R, GOSSELIN H, CALDERONE A, PERRAULT LP: Female rats fed a high-fat diet were associated with vascular dysfunction and cardiac fibrosis in the absence of overt obesity and hyperlipidemia: Therapeutic potential of resveratrol. J Pharmacol Exp Ther 325: 961-968, 2008.

BAE S, ZHANG L: Gender differences in cardioprotection against ischemia/reperfusion injury in adult rat hearts: Focus on Akt and protein kinase C signaling. J Pharmacol Exp Ther 315: 1125-1135, 2005.

BARRETT-CONNOR E: Sex differences in coronary heart disease. Why are women so superior? The 1995 Ancel Keys Lecture. Circulation 95: 252-264, 1997.

BATTERHAM RL, COWLEY MA, SMALL CJ, HERZOG H, COHEN MA, DAKIN CL, WREN AM, BRYNES AE, LOW MJ, GHATEI MA, CONE RD, BLOOM SR: Gut hormone PYY(3-36) physiologically inhibits food intake. Nature 418: 650-654, 2002.

BERG AH, COMBS TP, DU X, BROWNLEE M, SCHERER PE: The adipocyte secreted protein Acrp30 enhances hepatic insulin action. Nature Med 7: 947-953, 2001.

BJÖRNTORP P: Visceral obesity: a "civilization syndrome”. Obesity Res 3: 206-222, 1993.

BODEN G, SHULMAN GI: Free fatty acids in obesity and type 2 diabetes: defining their role in the development of insulin resistance and $\beta$-cell dysfunction. Eur J Clin Invest 32: 14-23, 2002.

BOURNE LT, LAMBERT EV, STEYN K: Where does the black population of South Africa stand on the nutrition transition? Public Health Nutr 5: 157-162, 2002.

COATMELLEC-TAGLIONI G, DAUSSE JP, GIUDICELLI Y, RIBIÈRE C: Sexual dimorphism in cafeteria dietinduced hypertension is associated with gender-related difference in renal leptin receptor down-regulation. J Pharmacol Exp Ther 305: 362-367, 2003.

COMBS TP, BERG AH, OBICI S, SCHERER PE, ROSSETTI L: Endogenous glucose production is inhibited by the adipose-derived protein Acrp30. J Clin Invest 108: 1875-1881, 2001.

CORDERO A, LEÓN M, ANDRÉS E, ORDOÑEZ B, LACLAUSTRA M, GRIMA A, PASCUAL I, LUENGO E, CIVEIRA F, POCOVÍ M, ALEGRÍA E, CASASNOVAS JA: MESYAS Registry investigators. Gender differences in obesity related cardiovascular risk factors in Spain. Prev Med 48: 134-139, 2009.

COSTACOU T, ZGIBOR JC, EVANS RW, OTVOS J, LOPES-VIRELLA MF, TRACY RP, ORCHARD TJ: The prospective association between adiponectin and coronary artery disease among individuals with type 1 diabetes. The Pittsburgh Epidemiology of Diabetes Complications Study. Diabetologia 48: 41-48, 2005.

CRABBE DL, DIPLA K, AMBATI S, ZAFEIRIDIS D: Gender differences in post-infarction hypertrophy in end-stage failing hearts. J Am Coll Cardiol 41: 300-306, 2003.

CROSS H, LU L, STEENBERGEN C, PHILIPSON K, MURPHY E: Overexpression of the cardiac Na+/Ca2+ exchanger increases susceptibility to ischemia/reperfusion injury in male, but not female, transgenic mice. Circ Res 83: 1215-1223, 1998.

CROSS H, KRANIAS E, MURPHY E, STEENBERGEN C: Ablation of PLB exacerbates ischemic injury to a lesser extent in female than male mice: protective role of NO. Am J Physiol 284: H683-H690, 2003.

CROSS H, MURPHY E, STEENBERGEN C: $\mathrm{Ca}^{2+}$ loading and adrenergic stimulation reveal male/female differences in susceptibility to ischemia-reperfusion injury. Am J Physiol 283: H481-H489, 2002.

DU TOIT EF, NABBEN M, LOCHNER A: A potential role for Angiotensin II in obesity induced cardiac hypertrophy and ischaemic/reperfusion injury. Basic Res Cardiol 100: 346-354, 2005.

Du TOIT EF, SMITH W, MULLER C, STRIJDOM H, STOUTHAMMER B, WOODIWISS AJ, NORTON GR, LOCHNER A: Myocardial susceptibility to ischemic-reperfusion injury in a prediabetic model of dietaryinduced obesity. Am J Physiol 294: H2336-H2343, 2008. 
FERDINANDY P, SZILVÁSSY Z, HORVÁTH LI, CSONT T, CSONKA C, NAGY E, SZENTGYÖRGYI R, NAGY I, KOLTAI M, DUX L: Loss of pacing-induced preconditioning in rat hearts: role of nitric oxide and cholesterol-enriched diet. J Mol Cell Cardio 29: 3321-3333, 1997.

FERRARA CM, GOLDBERG AP, NICKLAS BJ, SORKIN JD, RYAN AS: Sex differences in insulin action and body fat distribution in overweight and obese middle-aged and older men and women. Appl Physiol Nutr Metab 33: 784-790, 2008.

FRUEBIS J, TSAO TS, JAVORSCHI S, EBBETS-REED D, ERICKSON MR, YEN FT, BIHAIN BE, LODISH HF: Proteolytic cleavage product of $30-\mathrm{kDa}$ adipocyte complement-related protein increases fatty acid oxidation in muscle and causes weight loss in mice. Proc Natl Acad Sci USA 98: 2005-2010, 2001.

GABEL SA, WALKER VR, LONDON RE, STENBERGEN C, KORACH KS, MURPHY E: Estrogen receptor beta mediates gender differences in ischemia/reperfusion injury. J Mol Cell Cardiol 38: 289-297, 2005.

GÓMEZ-PÉREZ Y, AMENGUAL-CLADERA E, CATALÀ-NIELL A, THOMÀS-MOYÀ E, GIANOTTI M, PROENZA AM, LLADÓ I : Gender dimorphism in high-fat-diet-induced insulin resistance in skeletal muscle of aged rats. Cell Physiol Biochem 22: 539-548, 2008.

GROHNÉ C, KAHLERT S, LÖBBERT K, VETTER H: Expression of oestrogen receptor $\alpha$ and $\beta$ in the rat heart: role of local oestrogen synthesis. $J$ Endocrinol 156: R1-R7, 1998.

HAYWARD CS, KELLY RP, COLLINS P: The roles of gender, the menopause and hormone replacement on cardiovascular function. Cardiovasc Res 46: 28-49, 2000.

HORTON TJ, GAYLES EC, PRACH PA, KOPPENHAFER TA, PAGLIASSOTTI MJ: Female rats do not develop sucrose-induced insulin resistance. Am J Physiol 272: R1571-R1576, 1997.

KENCHAIAH S, EVANS JC, LEVY D, WILSON PWF, BENJAMIN EJ, LARSON MG, KANNEL WB, VASAN RS: Obesity and the risk of heart failure. New Eng J Med 347: 305-313, 2002.

KHAN MK, BOWMAN B: Obesity: a major public health problem. Annual Review of Nutrition 19: xiii-xvii, 1999.

KRAEGEN EW, CLARK PW, JENKINS AB, DALEY EA, CHISHOLM DJ, STORLIEN LH: Development of muscle insulin resistance after liver insulin resistance in high-fat-fed rats. Diabetes 40: 1397-1403, 1991.

KRUGER HS, PUOANE T, SENEKAL M, VAN DER MERWE MT: Obesity in South Africa: challenges for government and health professionals. Public Health Nutr 8: 491-500, 2005.

KUBOTA N, TERAUCHI Y, YAMAUCHI T, KUBOTA T, MOROI M, MATSUI J, ETO K, YAMASHITA T, KAMON J, SATOH H, YANO W, FROGUEL P, NAGAI R, KIMURA S, KADOWAKI T, NODA T: Disruption of adiponectin causes insulin resistance and neointimal formation. J Biol Chem 277: 25863-25866, 2002.

LOPASCHUK GD, FOLMES CDL, STANLEY WC: Cardiac energy metabolism in obesity. Circ Res 101: 335-347, 2007.

LOPASCHUK GD, REBEYKA IM, ALLARD MF: Metabolic modulation: a means to mend a broken heart. Circulation 105: 140-142, 2002.

LOUET JF, LEMAY C, MAUVAIS-JARVIS F: Antidiabetic actions of estrogen: insight from human and genetic mouse models. Curr Atheroscler Rep 6: 180-185, 2004.

MACINTYRE UE, KRUGER HS, VENTER CS, VORSTER HH: Dietary intake of an African population in different stages of transition in the North West Province, South Africa, the THUSA study. Nutrition Research 22: 239256, 2002.

MEHELLI J, KASTRATI A, DIRSCHINGER J, PACHE J, SEYFARTH M, BLASINI R, HALL D, NEUMANN FJ, SCHOMIG A: Sex-based analysis of outcome in patients with acute myocardial infarction treated predominantly with percutaneous coronary intervention. $J$ Am Med Assoc 287: 210-215, 2002.

MOSCA L, BANKA CL, BENJAMIN EJ, BERRA K, BUSHNELL C, DOLOR RJ, GANIATS TG, GOMES AS, GORNIK HL, GRACIA C, GULATI M, HAAN CK, JUDELSON DR, KEENAN N, KELEPOURIS E, MICHOS ED, NEWBY LK, OPARIL S, OUYANG P, OZ MC, PETITTI D, PINN VW, REDBERG RF, SCOTT R, SHERIF K, SMITH SC JR, SOPKO G, STEINHORN RH, STONE NJ, TAUBERT KA, TODD BA, URBINA E, WENGER NK: Expert Panel/Writing Group; American Heart Association; American Academy of Family Physicians; American College of Obstetricians and Gynecologists; American College of Cardiology Foundation; Society of Thoracic Surgeons; American Medical Women's Association; Centers for 
Disease Control and Prevention; Office of Research on Women's Health; Association of Black Cardiologists; American College of Physicians; World Heart Federation; National Heart, Lung, and Blood Institute; American College of Nurse Practitioners. Evidence-based guidelines for cardiovascular disease prevention in women: 2007 update. Circulation 115: 1481-501, 2007.

OPIE LH: The Heart; Physiology, from Cell to Circulation. $3^{\text {rd }}$ Edition. Raven Press, Philadelphia, NY, Chapter 11, 1998, pp 295-342.

PEDERSEN SB, KRISTENSEN K, HERMANN PA, KATZENELLENBOGEN JA, RICHELSEN B: Estrogen controls lipolysis by up-regulating alpha2A-adrenergic receptors directly in human adipose tissue through the estrogen receptor alpha. Implications for the female fat distribution. J Clin Endocrinol Metab 89: 1869-1878, 2004.

PICKAVANCE L, TADAYYON M, WIDDOWSON PS, BUCKINGHAM RE, WILDING JP: Therapeutic index for rosiglitazone in dietary obese rats: separation of efficacy and haemodilution. Br J Pharmacol 128: 1570-1576, 1999.

POIRIER P, GILES TD, BRAY GA, HONG Y, STERN JS, PI-SUNYER FX, ECKEL RH: Obesity and cardiovascular disease: pathophysiology, evaluation, and effect of weight loss: an update of the 1997 American Heart Association Scientific Statement on Obesity and Heart Disease from the Obesity Committee of the Council on Nutrition, Physical Activity, and Metabolism. American Heart Association; Obesity Committee of the Council on Nutrition, Physical Activity, and Metabolism. Circulation 113: 898-918, 2006.

RANKI HJ, BUDAS GR, CRAWFORD RM, JOVANOVIĆ A: Gender-specific difference in cardiac ATP-sensitive K ${ }^{+}$ channels. J Am Coll Cardiol 38: 906-915, 2001.

REGITZ-ZAGROSEK V, LEHMKUHL E, MAHMOODZADEH S: Gender aspects of the role of the metabolic syndrome as a risk factor for cardiovascular disease. Gend Med 4: S162-S177, 2007.

RINCON J, HOLMÄNG A, WAHLSTRÖM EO, LÖNNROTH P, BJÖRNTORP P, ZIERATH JR, WALLBERGHENRIKSSON H: Mechanisms behind insulin resistance in rat skeletal muscle after oophorectomy and additional testosterone treatment. Diabetes 45: 615-621, 1996.

ROACH PD, BALASUBRAMANIAM S, HIRATA F, ABBEY M, SZANTO A, SIMONS LA, NESTEL PJ: The lowdensity lipoprotein receptor and cholesterol synthesis are affected differently by dietary cholesterol in the rat. Biochim Biophys Acta 1170: 165-172, 1993.

ROSSOUW JE, ANDERSON GL, PRENTICE RL, LACROIX AZ, KOOPERBERG C, STEFANICK ML: Risk and benefits of estrogen plus progestin in healthy postmenopausal women: principal results From the Women's Health Initiative randomized controlled trial. JAMA 288: 321-333, 2002.

RYO M, NAKAMURA T, KIHARA S, KUMADA M, SHIBAZAKI S, TAKAHASHI M, NAGAI M, MATSUZAWA Y, FUNAHASHI T: Adiponectin as a biomarker of the metabolic syndrome. Circ J 68: 975-981, 2004.

SOWERS JR: Obesity as a cardiovascular risk factor. Am J Med 115: 37S-40S, 2003.

STEFAN N, VOZAROVA B, FUNAHASHI T, MATSUZAWA Y, WEYER C, LINDSAY RS, YOUNGREN JF, HAVEL J, PRATLEY RE, BOGARDUS C, TATARANNI A: Plasma adiponectin concentration is associated with skeletal muscle insulin receptor tyrosine phosphorylation, and low plasma concentration precedes a decrease in whole-body insulin sensitivity in humans. Diabetes 50: 1884-1888, 2002.

THAKKER GD, FRANGIOGIANNIS NG, BUJAK M, ZYMEK P, GAUBATZ JW, REDDY AK, TAFFET G, MICHAEL LH, ENTMANN ML, BALANTYNE CM: Effect of diet induced obesity on inflammation and remodeling after myocardial infarction. Am J Physiol Heart Circ Physiol 291: H2504-H2514, 2006.

THIM T, BENTZON JF, KRISTIANSEN SB, SIMONSEN U, ANDERSEN HL, WASSERMANN K, FALK E: Size of myocardidal infarction induced by ischaemia/reperfusion is unaltered in rats with metabolic syndrome. Clin Sci 110: 665-671, 2006.

TURNER N, BRUCE CR, BEALE SM, HOEHN KL, SO T, ROLPH MS, COONEY GJ: Excess lipid availability increases mitochondrial fatty acid oxidative capacity in muscle: evidence against a role for reduced fatty acid oxidation in lipid-induced insulin resistance in rodents. Diabetes 56: 2085-2092, 2007.

TUUNANEN H, ENGBLOM E, NAUM A, KJELL N, HESSE B, AIRAKSINEN J, NUUTILA P, IZZO P, UKKONEN H, OPIE LH, KNUUTI J: Free fatty acid deleption acutely decreases cardiac work and efficiency in cardiomyopathic heart failure. Circulation 114: 130-2137, 2006. 
VISTISEN B, HELLGREN LI, VADSET T, SCHEEDE-BERGDAHL C, HELGE JW, DELA F, STALLKNECHT B: Effect of gender on lipid-induced insulin resistance in obese subjects. Eur J Endocrinol 158: 61-68, 2008.

WALLHAUS TR, TAYLOR M, DEGRADO TR, RUSSELL DC, STANKO P, NICKLES RJ, STONE CK: Myocardial free fatty acid and glucose used after carvedilol treatment in patients with congestive heart failure. Circulation 103: 2441-2446, 2001.

WANG M, CRISOSTOMO P, WAIRIUKO GM, MELDRUM DR: Estrogen receptor-alpha mediates acute myocardial protection in females. Am J Physiol 290: H2204-H2209, 2006.

YAMAUCHI T, JAMON J, WAKE H, TERAUCHI Y, KUBOTA N, HARA K, MORI Y, IDE T, MURAKAMI K, TSUBOYANA-KASAOKA N, EZAKI O, AKANUMA Y, GAVRILOVA O, VINSON C, REITMAN ML, KAGECHIKA H, SHUDO K, YODA M, NAKANO Y, TOBE K, NAGAI R, KIMURA S, TOMITA M, FROGUEL P, KADOWAKI T: The fat-derived hormone adiponectin reverses insulin resistance associated with both lipoatrophy and obesity. Nature Med 7: 941-946, 2001.

YUSUF S, HAWKEN S, OUNPUU S, BAUTISTA L, FRANZOSI MG, COMMERFORD P, LANG CC, RUMBOLDT Z, ONEN CL, LISHENG L, TANOMSUP S, WANGAI P, RAZAK F, SHARMA AM, ANAND S: Obesity and the risk of myocardial infarction in 27000 participants from 52 countries: A case control study. Lancet 366: 1640-1649, 2005. 